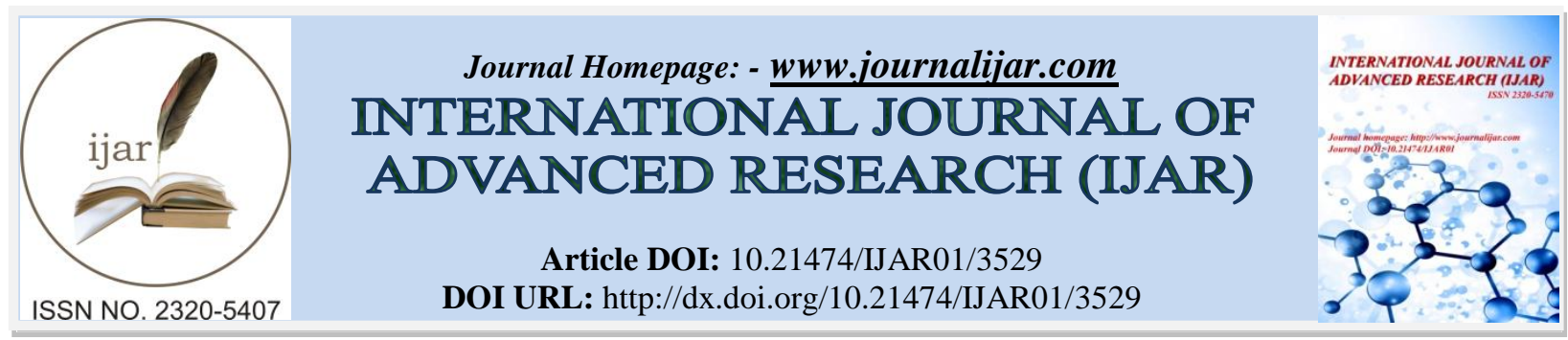

RESEARCH ARTICLE

\title{
DENTO-ALVEOLAR EFFECTS OF MEMORAX VERSUS HYRAX RAPID PALATAL EXPANDERS: A COMPARATIVE CBCT STUDY.
}

Tarek Hassan Marei and Fatma Abdel Aziz Abdel Samad.

Associate Professor, Department of Orthodontics, Faculty of Dental Medicine for girls, Al-Azhar University,Cairo, Egypt.

\section{Manuscript Info}

Manuscript History

Received: 12 January 2017

Final Accepted: 13 February 2017

Published: March 2017

Key words:-

Memorax, Hyrax, RME, RPE, CBCT,

Orthodontics

\section{Abstract}

Background: Rapid maxillary expansion usually associated with dental tipping of the anchor teeth, but the aims of the treatment are always to achieve minimal dental and maximum skeletal effects. The objective of the present study was to evaluate and compare the effect of memory palatal split screw (Memorax) to that of conventional Hyrax rapid palatal expanders on dento-alveolar structures, which were measured and recorded by Cone beam computed tomography (CBCT).

Materials and Methods: It was conducted over 14 subjects of adolescent patients with bilaterally constricted maxillary arch, with age ranged from 12 ys to $15 y$, with a mean of $13.6 \pm 1.4$ divided equally into two groups; the Memorax group and the Hyrax group. For all subjects, maxillofacial CBCTs were taken before expansion $\left(\mathbf{T}_{1}\right)$ and after 3 months at the time of removal of the expanders $\left(\mathbf{T}_{2}\right) .10$ dental measurements were taken (5 linear and 5 angular). Data were explored for normality using Kolmogorov-Smirnov test of normality. Paired $t$ test was used to compare mean values of before and after treatment. Independent (unpaired) test was used to compare between the two groups.

Results: There was no significant difference in the percent change after using both expanders, except in the inter-premolar apex width, where the percent change was significantly greater in the Memorax group ( $\mathrm{p}=0.0082)$, and in the inter-premolar angle, where the percent change was significantly greater in the Hyrax group $(\mathrm{p}=0.0096)$,

Conclusion: In the premolar area, Memorax produced bodily movement expansion pattern, while Hyrax showed more tipping of the anchor teeth.

Copy Right, IJAR, 2017,. All rights reserved.

\section{Introduction:-}

Interest in rapid maxillary expansion (RME) has increased during the past four decades. In spite of the recommended use of the RME for different aims, its fundamental objective is to increase the transverse width of the upper dental arch at the apical base (Sarver and Johnston, 1989). Although the major treatment aim of RME could be observed in the transversal expansion of the skeletal facial structures, dento-alveolar changes may be considered as an additional contribution or side effect.

Corresponding Author:- Tarek Hassan Marei.

Address:- Associate Professor, Department of Orthodontics, Faculty of Dental Medicine for girls, Al- 
Usually, appliances with fixed jack screw are used for RME and they produce heavy forces which when applied to the maxillary anchor teeth and alveolar structures exceed the limits required for orthodontic movement (Isaacson and Ingram, 1964, and Zimring and Isaacson, 1965). Pressure caused by the applied forces compresses the periodontal ligament of the anchorage teeth and subsequently produces orthopedic movement by opening the midpalatal suture (Haas A J, 1961) and orthodontic movement by tipping the upper posterior teeth and bending the alveolar bone (Da Silva Filho et al, 1991, Ciambotti et al, 2001, Oliveira et al, 2004, Kılıç et al, 2008, Braun et al, 2000, Asanza et al, 1997 and Garrett et al,2008) with both slow maxillary expansion (Hicks, 1978) as well as RME. Hence, the aim of the RME treatment is to achieve minimal dental and maximum skeletal effects (Haas, 1961). Many different RME appliances have been developed for this purpose.

A study (Wichelhaus A, Geserick M and Ball J, 2004) described and evaluated a new maxillary memory palatal split screw (Memorax) that includes nickel-titanium open coil springs in the screw bed in order to lessen the massive expansion forces. The screw could be activated six times a day to produce a constant force level of 12-14 N (12241428 grams) providing effective and rapid expansion. According to the authors, this new screw could produce rapid, constant, and physiological expansion forces, thus making the expansion procedure more effective, more physiological, and well tolerated by patients. However, another study (Halıcioğluet al, 2010) showed that memory palatal split screw produced significant increase in the inter-premolar and intermolar distances and reduced the nasal airway resistance.

In other studies,-the authors investigated effects of conventional Hyrax screw (Timms D J, 1981) and compared it with the memory screw on skeletal and dento-alveolar structures (Halıcıoğlu and Yavuz, 2011). They used plaster models and postero-anterior cephalograms at pretreatment $\left(\mathrm{T}_{1}\right)$, after expansion $\left(\mathrm{T}_{2}\right)$, and after retention $\left(\mathrm{T}_{3}\right)$. They found that the use of memory screw may be advantageous because it shortens the maxillary expansion period, provides additional expansion in the retention period, and generates light forces relative to the conventional Hyrax screw. Although studies about memory screw have increased, further investigations are still needed to compare the effects of RME caused by memory screw and Hyrax screw on the dento-facial structures. The aim of the present study is to investigate and compare the transversal dento-alveolar changes in subjects treated with a Memorax screw and conventional Hyrax screw using CBCT.

\section{Methods:-}

The material of this study consisted of CBCT radiographs of 14 patients, with bilateral maxillary cross-bite caused by basal apical narrowness, who were planned for RME at the Department of Orthodontics, Faculty of Dental Medicine for Girls, Al- Azhar University, Cairo, Egypt.

The research proposal was approved by the research ethics committee (REC), Faculty of Dental Medicine for Girls, Al- Azhar University, Cairo, Egypt. The detailed procedure was discussed with the patients and their guardians who signed an informed consent before the start of the clinical work.

The subjects were randomly divided into two equal groups: memory-screw group (Memorax group) treated using Memorax RME appliance (Product number: 167M1529-Memory expander type 'N'; Forestadent, Pforzheim, Germany). This group comprised 7 subjects (6 females and 1 male) with ages ranged from 13.6 \pm 1.4 years, and Hyrax-screw group treated using Hyrax RME appliance (Product Type: 602-808-10 Hyrax ${ }^{\circledR}$ Medium, Dentaurum, Ispringen, Germany). This group also comprised 7 subjects (6 females and 1 male) with ages ranged from $13.5 \pm 0.4$ years. Maxillary first premolars and first molars were banded and four-armed expansion screws were soldered to the bands in both groups. In the conventional Hyrax-screw group, the patients were instructed to activate the screw two quarter-turns a day $(0.2 \times 2=0.4 \mathrm{~mm})$ one in the morning and one in the evening, while in the Memorax group, the patients were instructed to activate the screw six quarter-turns a day $(0.2 \times 6=1.2 \mathrm{~mm})$; two in the morning, two after lunch, and two in the evening. Both screws were activated until the occlusal aspect of the maxillary lingual cusp of the upper first molars contacted the occlusal aspect of the facial cusp of the mandibular first molars, thus producing the desiring expansion. The mean expansion period was 7 days in the memory-screw group and 22 days in the Hyrax-screw group with average total screw quart-turns in both group was $42(8.4 \mathrm{~mm})$ and $44(8.8 \mathrm{~mm})$ respectively. Then, patients were left with the appliances as retainers for 3 months with the fixation of the screw of the hyrax group according to manufacturer instructions (Fig 1).

CBCT imaging: the RME achieved in this study was evaluated using Next Generation Scanora 3D CBCT scanner (Soredex, Tuusula, Finland). Images were taken prior to treatment (T1), and 3 months after removing the appliance 
(T2). The machine was set to the following protocol for all the scans of the study: $90 \mathrm{kVp}, 4 \mathrm{~mA}$, Voxel size $0.35 \mathrm{~mm}$, Scanning time was 45 seconds, with Field of view 13 x $13 \mathrm{~cm}$.

After acquisition, data were exported and transferred in DICOM format to be secondarily re-evaluated for linear and angular measurement, where Invivo Dental software (version 5.3; Anatomage, San Jose, California, USA) was used for that purpose.

Invivo software was employed to superimpose preoperative and postoperative scans. The set of DICOM data of the preoperative scan was loaded into the software, and then the set of the postoperative scan of the same patient was loaded over it at the superimposition module. According to variation in positioning of both scans, a second adjustment was needed to ensure perfect superimposition, hence guaranteeing measuring linear and angular measurements at the exact level. Superimposition module was used to superimpose the postoperative scan over the preoperative one, where four landmarks, at different planes, were chosen at each scan, and then registration of these landmarks was automatically performed by the software. Superimposition sequence was repeated for each patient individually (Fig 2).

After completion of superimposition, the two scans (preoperative and postoperative) were regarded as a one unit and moved in the same manner. Orientation of the whole volume was made to ensure that the orthogonal reference lines (axial, coronal and sagittal) were following certain planes. Axial line was made parallel to maxillary plane (ANSPNS) at sagittal view and parallel to the nasal floor at the coronal view respectively, and the sagittal line was parallel to the mid-sagittal plane at the coronal view (Fig 3). Ten dental measurements were recorded; five linear and five angular measurements (Table 1). For linear measurements, coronal view was utilized, where coronal reference line was moved to intersect at the palatal roots of the upper first molars at both sides. At the produced view, maxillary base width and inter-molar width (between apices of palatal roots and mesio-buccal cusp tips bilaterally) were measured at pre-operative scan then it was hidden then the same measurements were taken at the same view for the post-operative scan (Fig 4). At the same view, angulation of right and left first molars were measured in the same manner, and also the inter-molar angle as well. Molar angulation was measured by drawing the angle connecting the mesio-buccal cusp tip to the palatal root tip intersecting with the axial line which was made parallel to the nasal fossa for this measurement (Fig 5). Same measurements were repeated at the first premolars level after moving the coronal view to that level.

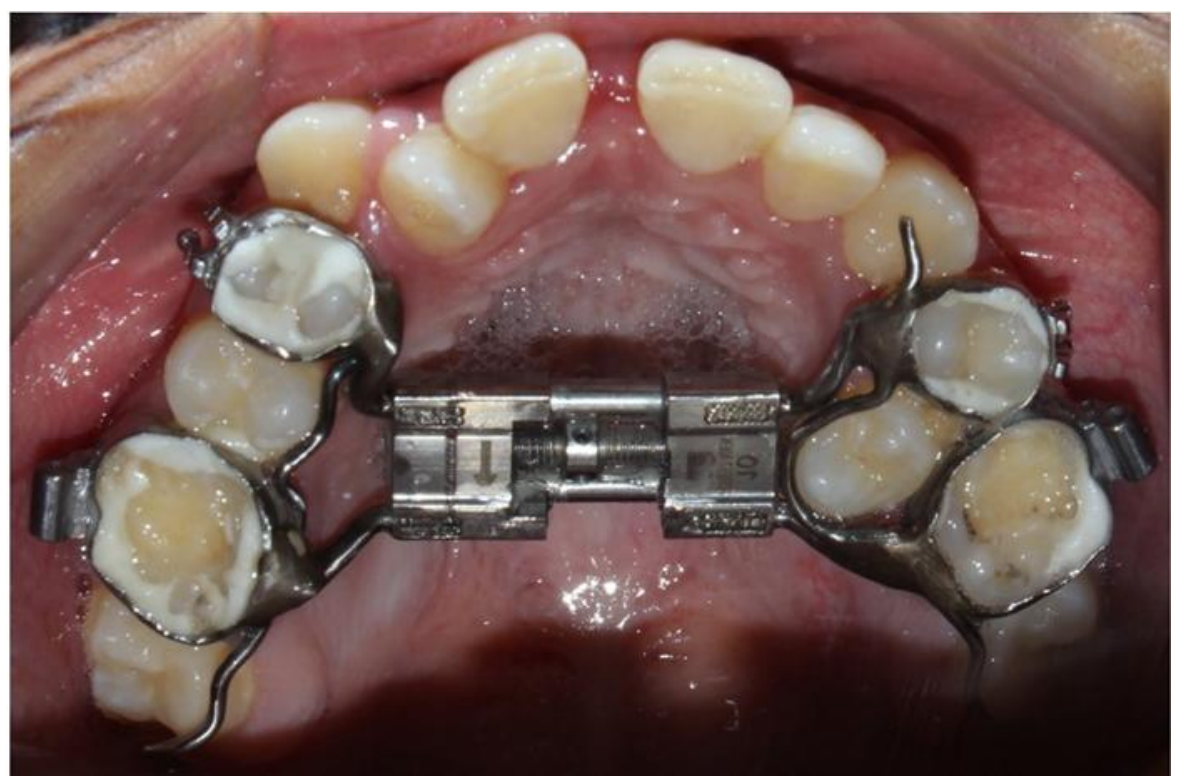

Figure 1:- Memorax rapid palatal expander during active expansion period. 


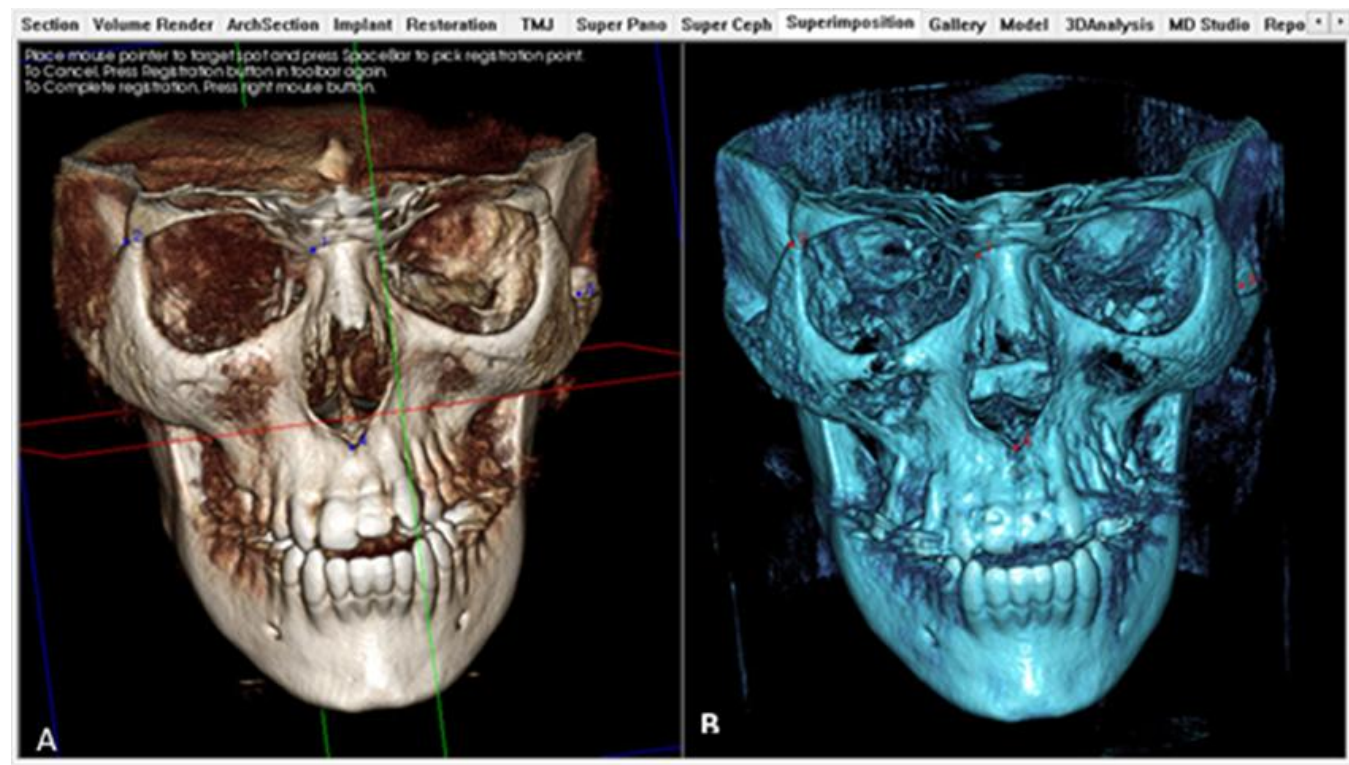

Figure 2: four landmarks, at different planes, numbered $(1,2,3,4)$ were chosen at each scan (A: Blue colored numbers in the Preoperative scan ), and then registration of these landmarks was automatically performed by the software (B: Red colored numbers in the postoperative scan).

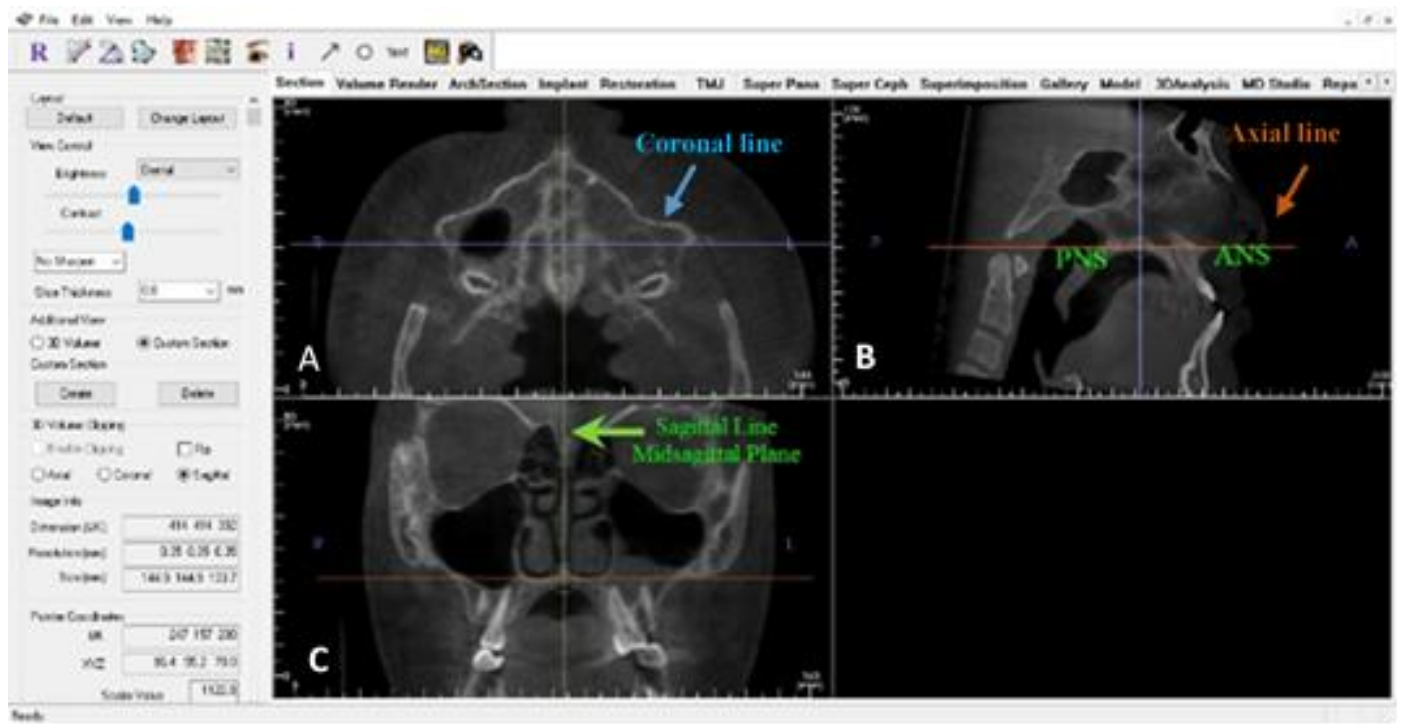

Figure 3:- orthogonal reference lines. (A: coronal line, B: Axial line, and C: sagittal line) 


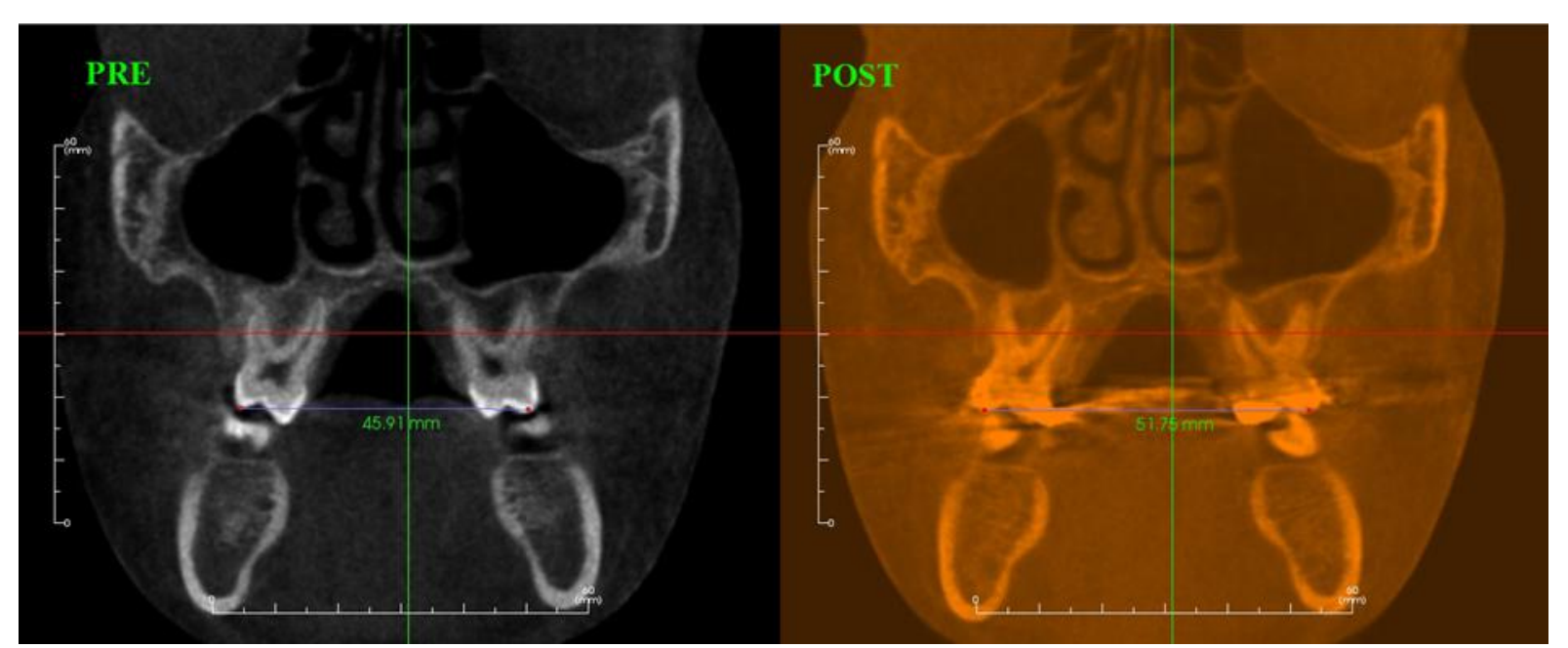

Figure 4:- coronal reference line was moved to intersect at mesio-buccal cusp tips bilaterally to measure the intermolar width in the pre- and post-operative scans.

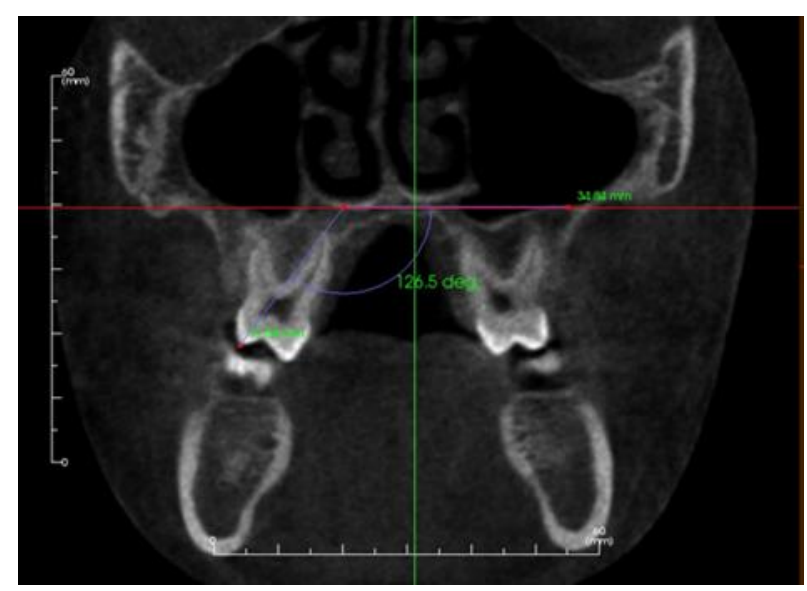

Figure 5: Molar angulation measurements.

\section{Results:-}

Values of all parameters were presented as mean and standard deviation (SD) values. Data were explored for normality using Kolmogorov-Smirnov test of normality. The results of Kolmogorov-Smirnov test indicated that most of data were normally distributed (parametric data), so parametric tests were used for the comparisons. Paired t-test was used to compare mean values of before and after treatment. Independent (unpaired) t-test was used to compare between the two groups. The percentage change after treatment was calculated as follows:

(after-treatment value - before-treatment value) X100/ before-treatment value.

The significance level was set at $p \leq 0.05$. Statistical analysis was performed with SPSS for Windows v.16.0 (SPSS Inc., USA).

Both linear (mm) and angular (degree) values increased after treatment in the Memorax group. Paired t test revealed that the difference was statistically significant for all measurements, except for the right premolar angle degree, where the increase after treatment didn't reach the level of statistical significance $(\mathrm{p}=0.0682)$ (Table 1). Both linear and angular values increased after treatment in the Hyrax group. Paired t test revealed that the difference was statistically significant for all measurements (Table 2). Unpaired t-test revealed no significant difference in the mean pretreatment values of both groups. Moreover, there was no significant difference in the mean post-treatment values of both groups. Unpaired t-test revealed no significant difference in the percent change after using both expanders, except in the inter-premolar apex width, where the percent change was significantly greater in the 
Memorax group ( $\mathrm{p}=0.0082)$, and in the inter-premolar angle, where the percent change was significantly greater in the Hyrax group $(\mathrm{p}=0.0096)$ (Table 3).

Table 1:- Pre-treatment $\left(T_{1}\right)$ and post-treatment $\left(T_{2}\right)$ values, percent change and significance of the difference using paired t-test in the Memorax group

\begin{tabular}{|c|c|c|c|c|c|c|c|c|c|c|c|}
\hline \multirow[t]{2}{*}{ Memorax } & \multicolumn{3}{|l|}{$\mathbf{T}_{1}$} & \multicolumn{3}{|l|}{$\mathbf{T}_{2}$} & \multicolumn{3}{|c|}{ Percent change } & \multirow[t]{2}{*}{ t value } & \multirow[t]{2}{*}{ P value } \\
\hline & Mean & SD & SE & Mean & SD & SE & Mean & SD & SE & & \\
\hline Maxillary base width & 61.41 & 4.74 & 1.69 & 63.20 & 4.80 & 1.81 & 2.93 & 2.22 & 0.84 & 3.44 & $0.0137 *$ \\
\hline $\begin{array}{l}\text { Inter-molar crown } \\
\text { width }\end{array}$ & 48.81 & 2.88 & 1.09 & 54.86 & 2.59 & 0.98 & 12.48 & 3.03 & 1.14 & 12.44 & $<0.0001 *$ \\
\hline Inter-molar apex width & 26.93 & 4.62 & 1.74 & 29.19 & 3.89 & 1.47 & 9.05 & 5.54 & 2.09 & 5.078 & $0.0022 *$ \\
\hline Right molar angulation & 119.17 & 7.51 & 2.83 & 125.86 & 5.11 & 1.93 & 5.76 & 3.18 & 1.2 & 5.165 & $0.0020^{*}$ \\
\hline Left molar angulation & 120.11 & 6.41 & 2.42 & 124.57 & 7.45 & 2.81 & 3.71 & 3.12 & 1.18 & 3.189 & $0.0188^{*}$ \\
\hline $\begin{array}{l}\text { Inter-premolar root } \\
\text { angle }\end{array}$ & 58.57 & 13.55 & 5.11 & 60.94 & 12.48 & 4.71 & 13.06 & 4.68 & 5.54 & 4.735 & $0.0032 *$ \\
\hline $\begin{array}{l}\text { Inter-premolar crown } \\
\text { width }\end{array}$ & 36.96 & 6.62 & 2.5 & 44.77 & 1.58 & 0.6 & 21.21 & 2.80 & 1.06 & 24.229 & $<0.0001^{*}$ \\
\hline $\begin{array}{l}\text { Inter-premolar apex } \\
\text { width }\end{array}$ & 24.94 & 6.31 & 2.38 & 28.86 & 6.04 & 2.28 & 16.94 & 9.52 & 3.59 & 4.248 & $0.0053 *$ \\
\hline Right premolar angle & 105.34 & 12.64 & 4.77 & 109.47 & 9.38 & 3.54 & 4.38 & 5.71 & 2.15 & 2.219 & $0.0682^{\mathrm{ns}}$ \\
\hline Left premolar angle & 108.09 & 6.91 & 2.61 & 113.37 & 5.97 & 2.25 & 5.01 & 3.93 & 1.48 & 3.3361 & $0.0156^{*}$ \\
\hline
\end{tabular}

SD: Standard Deviation, SE: Standard Error, ns: non-significant, ${ }^{*}$ : significant at $\mathrm{p}<0.05$

Table 2:- Pre-treatment $\left(T_{1}\right)$ and post-treatment $\left(T_{2}\right)$ values, percent change and significance of the difference using paired $t$ test in the Hyrax group

\begin{tabular}{|c|c|c|c|c|c|c|c|c|c|c|c|}
\hline \multirow[t]{2}{*}{ Hyrax } & \multicolumn{3}{|r|}{$\mathbf{T}_{1}$} & \multicolumn{3}{|r|}{$\mathbf{T}_{2}$} & \multicolumn{3}{|c|}{ Percent change } & \multirow{2}{*}{$\begin{array}{r}t \\
\text { value }\end{array}$} & \multirow[t]{2}{*}{ P value } \\
\hline & $\begin{array}{r}\text { Mea } \\
\mathbf{n}\end{array}$ & $\begin{array}{l}\text { S } \\
\text { D }\end{array}$ & $\mathbf{S E}$ & Mean & SD & SE & Mean & SD & SE & & \\
\hline Maxillary base width & $\begin{array}{r}58.1 \\
6\end{array}$ & $\begin{array}{l}4 . \\
46\end{array}$ & $\begin{array}{r}1.6 \\
8\end{array}$ & 60.63 & 5.30 & 2 & 4.19 & 1.63 & 0.62 & 6.1177 & $0.00087 *$ \\
\hline $\begin{array}{l}\text { Inter-molar crown } \\
\text { width }\end{array}$ & $\begin{array}{r}49.6 \\
9\end{array}$ & $\begin{array}{l}4 . \\
21\end{array}$ & $\begin{array}{r}1.5 \\
9\end{array}$ & 56.73 & 6.26 & 2.36 & 14.14 & 6.97 & 2.63 & 5.2158 & $0.00198 *$ \\
\hline Inter-molar apex width & $\begin{array}{r}28.3 \\
1\end{array}$ & $\begin{array}{c}3 . \\
11\end{array}$ & $\begin{array}{r}1.1 \\
7\end{array}$ & 29.90 & 4.18 & 1.58 & 5.33 & 4.65 & 1.72 & 2.896 & $0.0274 *$ \\
\hline Right molar angulation & $\begin{array}{r}117 . \\
93 \\
\end{array}$ & $\begin{array}{l}1 . \\
91\end{array}$ & $\begin{array}{r}0.7 \\
2 \\
\end{array}$ & $\begin{array}{r}125.6 \\
9 \\
\end{array}$ & 4.78 & 1.8 & 6.55 & 2.80 & 1.06 & 6.0813 & $0.00089 *$ \\
\hline Left molar angulation & $\begin{array}{r}123 . \\
83 \\
\end{array}$ & $\begin{array}{c}1 . \\
79\end{array}$ & $\begin{array}{r}0.6 \\
8\end{array}$ & $\begin{array}{r}131.9 \\
6 \\
\end{array}$ & 8.34 & 3.15 & 6.51 & 5.39 & 2.03 & 3.1857 & $0.0189 *$ \\
\hline $\begin{array}{l}\text { Inter premolar root } \\
\text { angle }\end{array}$ & $\begin{array}{r}69.2 \\
0 \\
\end{array}$ & $\begin{array}{c}5 . \\
14 \\
\end{array}$ & $\begin{array}{r}1.9 \\
4 \\
\end{array}$ & 79.41 & 8.94 & 3.37 & 14.49 & 4.59 & 1.73 & 6.9434 & $0.0004 *$ \\
\hline $\begin{array}{l}\text { Interpremolar crown } \\
\text { width }\end{array}$ & $\begin{array}{r}39.6 \\
4 \\
\end{array}$ & $\begin{array}{r}6 . \\
40\end{array}$ & $\begin{array}{r}2.4 \\
2\end{array}$ & 46.96 & 5.79 & 2.18 & 18.11 & 7.73 & 3.02 & 5.4499 & $0.00158 *$ \\
\hline $\begin{array}{l}\text { Interpremolar apex } \\
\text { width }\end{array}$ & $\begin{array}{r}27.4 \\
3 \\
\end{array}$ & $\begin{array}{c}7 . \\
17 \\
\end{array}$ & $\begin{array}{r}2.7 \\
1 \\
\end{array}$ & 28.57 & 7.27 & 2.74 & 4.38 & 4.47 & 1.69 & 3.0044 & $0.02387 *$ \\
\hline Right premolar angle & $\begin{array}{r}103 . \\
64 \\
\end{array}$ & $\begin{array}{r}6 . \\
54\end{array}$ & $\begin{array}{r}2.4 \\
7 \\
\end{array}$ & $\begin{array}{r}115.2 \\
3 \\
\end{array}$ & 5.87 & 2.22 & 11.26 & 1.57 & 0.59 & 32.588 & $<0.0001 *$ \\
\hline Left premolar angle & $\begin{array}{r}107 . \\
53\end{array}$ & $\begin{array}{r}3 . \\
71\end{array}$ & 1.4 & $\begin{array}{r}114.7 \\
6\end{array}$ & 3.69 & 1.44 & 6.84 & 5.27 & 1.99 & 3.566 & $0.00118^{*}$ \\
\hline
\end{tabular}

SD: Standard Deviation $\quad$ SE: Standard Error *significant at $\mathrm{p}<0.05$ 
Table 3:- Comparison of percent change in dento-alveolar effects in both Memorax and Hyrax group

\begin{tabular}{|l|r|r|r|r|}
\hline & \multicolumn{2}{l|}{ Percent change [Mean (SD)] } & t value & \multirow{2}{*}{ P value } \\
\cline { 2 - 4 } & Memorax & Hyrax & & \\
\hline Maxillary base width & $2.93(2.22)$ & $4.19(1.63)$ & 1.2104 & $0.249^{\mathrm{ns}}$ \\
\hline Inter-molar crown width & $12.48(3.03)$ & $14.14(6.97)$ & 0.5779 & $0.574^{\mathrm{ns}}$ \\
\hline Inter-molar apex width & $9.05(5.54)$ & $5.33(4.65)$ & 1.3608 & $0.198^{\mathrm{ns}}$ \\
\hline Right molar angulation & $5.76(3.18)$ & $6.55(2.80)$ & 0.4933 & $0.603^{\mathrm{ns}}$ \\
\hline Left molar angulation & $3.71(3.12)$ & $6.51(5.39)$ & 1.1895 & $0.2572^{\mathrm{ns}}$ \\
\hline Inter premolar root angle & $13.06(4.68)$ & $14.49(5.59)$ & 1.4742 & $0.1662^{\mathrm{ns}}$ \\
\hline Interpremolar crown width & $21.21(2.80)$ & $18.11(7.73)$ & 0.9976 & $0.3382^{\mathrm{ns}}$ \\
\hline Interpremolar apex width & $16.94(9.52)$ & $4.38(4.47)$ & 3.1596 & $0.0082^{*}$ \\
\hline Right premolar angle & $4.38(5.71)$ & $11.26(1.57)$ & 3.0738 & $0.0096^{*}$ \\
\hline Left premolar angle & $5.01(3.93)$ & $6.84(5.27)$ & 0.7365 & $0.4756^{\mathrm{ns}}$ \\
\hline
\end{tabular}

(SD): (Standard Deviation), ns: non-significant, *: significant at $\mathrm{p}<0.05$

\section{Discussion:-}

Generally, RME screw is turned twice a day during expansion. Isaacson and Ingram (1964) and Zimring and Isaacson (1965) suggested turning the screw twice until the suture opens in adolescent people and recommended that slower rates of expansion would allow for physiologic adjustment at the maxillary articulations and prevent residual force. In this study, the Hyrax screw was activated twice daily even after the suture has opened to stabilize the force applied to the appliance from the start till the end of expansion period. While in the Memorax group, screw was activated six times a day during RME. The difference between the screw activation protocols results from the different levels of forces produced by screws. Isaacson and Ingram (1964) measured the forces produced by conventional RME appliance and found that a quarter turns of the screw produced heavy and intermittent forces ranging from 1.5 to $4 \mathrm{~kg}$, and may accumulate up to approximately $10 \mathrm{~kg}$. However, Wichelhaus et al. (2004) evaluated that memory screw activated six times a day could generate a continuous force ranging from 1.225 to $1.425 \mathrm{~kg}$. Additionally, Zimring and Isaacson (1965) hypothesized that if the expansion procedure was carried out at lower force level in a shorter treatment time, the total expansion might be physiologically stable. In the current study, adequate maxillary expansion was accomplished with the Memorax screw in 7 days with relatively lower forces than that produced by conventional expanders. However, the results of the present study shared to support the hypotheses of Zimring and Isaacson (1965) and Isaacson and Ingram (1964).

Both linear and angular values increased after treatment with both Memorax and Hyrax. Paired t-test revealed that the difference was statistically significant for all measurements, except for the right premolar angle degree in the Memorax group, where the increase after treatment did not reach the level of statistical significance. While there was no significant difference in the percent change after using both expanders, except in the inter-premolar apex width, where the percent change was significantly greater in the Memorax group $(\mathrm{p}=0.0082)$ which revealed a bodily movement pattern in the premolars area. In the Hyrax group, the percent change in the inter-premolar angle was significantly greater $(\mathrm{p}=0.0096)$ than the Memorax group which revealed a more tipping movement in the premolar area. These results could be regarded to the fact that the memory screw provided additional expansion in the retention period, which might have probably resulted from the activation of the nickel-titanium springs. In other words, in the retention period, nickel-titanium springs integrated in the screw might have not only resisted the residual forces that are considered to be the source of relapse, but according to Halıcioğlu et al (2010), it also produce further expansion during the retention period. It was also observed that expansion with Hyrax led to a more tipping movement in the right rather than the left premolar, which may be attributed to the design of the Hyrax appliance used in the study. Braun et al (2000) demonstrated that the amount of dento-alveolar tipping depends on factors, such as the type of expansion appliance, age of the patient, resistance of the surrounding tissues, and schedule of screw activation. It has been observed that the rigidity of the expansion appliance is one of the factors responsible for decreasing the buccal tipping of the anchorage teeth (Timms, 1981). Although many different RME appliances have been developed to minimize the dento-alveolar inclination (Memikoglu and İşeri, 1999 and Başçiftçi and Karaman, 2002), occurrence of dento-alveolar tipping is unavoidable (Wertz, 1970 and Bishara and Staley, 1978). Asanza et al (1997) and Ciambotti et al (2001) found less molar tipping in patients treated with a Hyrax expander according to their studies. This difference may owe to the different measurement techniques employed for the determination of inclination. While Garrett et al(2008) showed that dento-alveolar inclination lacks significant correlations with the schedule of screw activation but correlate well with the amount of expansion. In the 
present study, both the screws produced statistically significant dento-alveolar molar tipping after expansion. According to Hicks (1978) the anchorage teeth are expected to tip during expansion and remain upright at retention. In our study, this occurred in the Hyrax group showing significant increase in dento-alveolar tipping in the anchor premolars (inter premolar angle) $(\mathrm{P}=0.0096)$. This did not occur in the Memorax group, as an almost bodily movement of the anchorage teeth took place during the expansion period. This was due to the decreased alveolar bending occurred as a skeletal response to the rapid physiological distribution of the force applied by the appliance, which resulted from the nickel-titanium springs in the screw. This produced a significant increase in the interpremolar apex width $(\mathrm{P}=0.0082)$. We believe that the continuous force exerted during retention, is the main reason behind preventing molar teeth to remain upright, producing non-significant dentoalveolar tipping in the anchored molars, which was decreased significantly in the premolar area. Hence, Memorax might increase the dento-alveolar tipping during the retention period especially in the molar area which might exceed the planned overexpansion if left more than 3 months. Halıcıoğlu K and Yavuz (2011) reported similar results when using Memorax for expansion, where the inter-premolar and molar width increased in the retention period. So they recommended before completing the active phase of RME, to take into account that some amount of increments will be observed in intermolar and interpremolar widths during the retention period. So according to previous findings which were emphasized during our study, The Memorax is not recommended to be left more than 3 months retention in the patient mouth.

\section{Conclusions:-}

Both appliances produced dento-alveolar tipping in the anchored teeth. But for the first premolars, Memorax produced a bodily movement expansion pattern with less dento-alveolar tipping. Om the other hand, Hyrax showed a more tipping movement of the anchor premolars and molars.

\section{Recommendations:-}

$>$ The Memorax is not recommended to be left more than 3 months as a retainer in the patient mouth as it increases the dento-alveolar tipping of the anchored teeth in the retention period.

$>$ Further investigations are needed to analyze the forces and stresses produced by the Memorax in both active expansion and retention periods.

\section{Acknowledgement:-}

We really acknowledge the effort done by Amira Allam (MSc., orthodontics) who effectively helped us in the clinical work as well as in CBCT procedure and measurements.

\section{References:-}

1. Asanza S, Cisneros G J, Nieberg L G. Comparison of Hyrax and bonded expansion appliances. Angle Orthod, 1997; 67: 15-22

2. Başçiftçi F A and KaramanA İ. Effects of a modified acrylic bonded rapid maxillary expansion appliance and vertical chin cap on dentofacial structures. Angle Orthod, 2002;72: 61-71

3. Bishara S E and Staley R N. Maxillary expansion: clinical implications. Am J Orthod Dentofac Orthop, 1987; 91: 3-14.

4. Braun S, Bottrel J A, Lee K G, Lunazzi J J and Legan H L. The biomechanics of rapid maxillary sutural expansion. Am J Orthod Dentofac Orthop, 2000; 118: 257-61

5. Ciambotti C, Ngan P, Durkee M, Kohli K and Kim H. A comparison of dental and dentoalveolar changes between rapid palatal expansion and nickel-titanium palatal expansion appliances. Am J Orthod Dentofac Orthop, 2001; 119: 11-20

6. Da Silva Filho O G, Boas M C and Capelozza Filho L. Rapid maxillary expansion in the primary and mixed dentitions: a cephalometric evaluation. Am J Orthod Dentofac Orthop, 1991; 100: 171-9

7. Garrett B, Caruso J, Rungcharassaeng K, Farrage J, Kim J, Taylor G. Skeletal effects to the maxilla after rapid maxillary expansion assessed with cone-beam computed tomography. Am J Orthod Dentofac Orthop, 2008; 134: 8.e1-e11

8. Haas A J. Rapid expansion of the maxillary dental arch and nasal cavity by opening the mid-palatal suture. Angle Orthod, 1961; 31: 73-89

9. Halıcıoğlu K and Yavuz I. Comparison of the effects of rapid maxillary expansion caused by treatment with either a memory screw or a Hyrax screw on the dentofacial structures - transversal effects. Eu J Orthod, 2011; 43: 1-10. 
10. Halıcıoğlu K, Kılıç N, Yavuz İ and Aktan B. Effects of rapid maxillary expansion with memory palatal split screw on the morphology of the maxillary dental arch and nasal airway resistance. Eu J Orthod, 2010; 32: 71620

11. Hicks E P. Slow maxillary expansion. A clinical study of the skeletal versus dental response to low-magnitude force. Am J Orthod, 1978; 73: 121-41.

12. Isaacson $\mathbf{R} \mathbf{J}$ and Ingram $\mathbf{A} \mathbf{H}$. Forces produced by rapid maxillary expansion. II. Forces present during treatment. Angle Orthod, 1964; 34: 261-70

13. Kılıç N, Kiki A and Oktay H. A comparison of dentoalveolar inclination treated by two palatal expanders. Eu J Orthod, 2008; 30: 67-72

14. Memikoglu $\mathbf{T} \mathbf{U}$ and İşeri $\mathbf{H}$. Effects of a bonded rapid maxillary expansion appliance during orthodontic treatment. Angle Orthod,1999; 69: 251-6

15. Oliveira N L, Da Silveira A C, Kusnoto B and Viana G. Three-dimensional assessment of morphologic changes of the maxilla: a comparison of 2 kinds of palatal expanders. Am J Orthod Dentofac Orthop, 2004; 126: $354-62$

16. Sarver D M and Johnston M W. Skeletal changes in vertical and anterior displacement of the maxilla with bonded rapid palatal expansion appliances. Am J Orthod Dentofac Orthop, 1989; 95: 462-6

17. Timms D J. Rapid maxillary expansion. Quintessence Publishing Co. Inc, Chicago, 1981. (Cited inHalıcioğlu $\mathrm{K}$ and Yavuz I. Comparison of the effects of rapid maxillary expansion caused by treatment with either a memory screw or a Hyrax screw on the dentofacial structures - transversal effects. Eu J Orthod, 2011; 43: 1$10)$.

18. Wertz R A. Skeletal and dental changes accompanying rapid mid-palatal suture opening. Am J Orthod, 1970; 58: 41-66.

19. Wichelhaus A, Geserick $\mathbf{M}$ and Ball J. A new nickel titanium rapid maxillary expansion screw. J Clinic Orthod, 2004; 38: 677-80

20. Zimring $\mathbf{J} \mathbf{F}$ and Isaacson $\mathbf{R} \mathbf{J}$. Forces produced by rapid maxillary expansion. 3. Forces present during retention. Angle Orthod, 1965; 35: 178-86. 